\title{
Psychotropic Agent
}

National Cancer Institute

\section{Source}

National Cancer Institute. Psychotropic Agent. NCI Thesaurus. Code C82395.

A classification of medication that acts on the central nervous system, affecting brain function, level of consciousness, mood, emotions, and behavior. 